\title{
Adult science learners' mathematical mistakes: An analysis of responses to computer-marked questions
}

\author{
Sally Jordan ${ }^{1}$ \\ ${ }^{1}$ Department of Physical Science, The Open University, UK \\ For correspondence: sally.jordan@open.ac.uk
}

\begin{abstract}
:
Inspection of thousands of student responses to computer-marked assessment questions has brought insight into the errors made by adult distance learners of science. Most of the questions analysed were in summative use and required students to construct their own response. Both of these things increased confidence in the reliability of the findings, as did the fact that similar errors were seen in different variants and in different questions. Questions on logarithms, graphs and gradient, differentiation and standard deviation were poorly answered. However, the most persistent errors, seen in questions designed to assess a range of different skills, were in rounding numerical values to an appropriate number of decimal places or significant figures and in working out the units of an answer. Other errors included incorrect precedence in calculations, giving symbols in an incorrect case, and problems with reciprocation, adding fractions, handling powers, performing unit conversions, and simplifying algebraic expressions. Possible reasons for the errors include careless slips, poor understanding of a method, and deeper conceptual misunderstandings. Many of the errors were similar to those reported by others, both at university and school level, and it appears that there are some very basic stumbling blocks that affect a wide range of students. It is suggested that increased use of discussion with students might bring further insight into the reasons for errors as well as increasing student understanding.
\end{abstract}

Keywords: mathematical errors; e-assessment; diagnostic testing; assessment analytics; learning analytics

\section{Introduction}

The 'maths problem', identified as a stumbling block for higher education students across a range of disciplines in science and engineering (e.g. Tariq et al, 2005; Engineering Council, 2000), is not new. Declining numeracy skills have been being reported since at least 1876 (Dearing, 1996) and 'it has always seemed that things were better 20 years ago' (Gill, 1999b, p.84). Although there is considerable variation between mathematical abilities of 15-year old students around the world (OECD, 2013), the maths problem at entry to university has been reported in many countries, for example Ireland (Gill and O'Donoghue, 2007) and Australia (Cuthbert and MacGillivray, 2002) as well as the UK (Croft et al, 2009). The longstanding and widespread nature of the problem mean that, whilst it may be attributed in part to differences in the school curriculum and to widening access to higher education (Williamson et al, 2003) and other changes such as over-reliance on calculators (Dearing, 1996), it is likely that it has its basis in more fundamental misconceptions.

A number of authors talk about the importance of building mathematical skills and understanding on a firm foundation, with useful analogies including a 'house of cards' in which 'the bottom layer must be firmly and accurately constructed if [the cards] are to support the next layer up'. (Butterworth, 1999, p. 298). Tobias (1978) highlights the sequential nature of mathematics in her description of the 'dropped stitch' problem, in which schoolchildren and adults struggle with more advanced mathematics if, for example, 'the day they introduced fractions I had the measles' (p. 55). Thus work on schoolchildren's mathematical misunderstandings is likely to be highly relevant for adult education (Rees and Barr, 1984), especially since there is often only slow development of mathematical understanding during the teenage years (Küchermann, 1981; Ryan and Williams, 2007). 
Several projects have analysed the mathematical misunderstandings of cohorts of children, either by inspection of large numbers of responses to questions in national tests (Williams and Ryan, 2000) or by the use of specially designed questions (Ryan and Williams, 2007), sometimes supplemented by interviews (Hart et al, 1981). Rees and Barr (1984) identified threshold 'core of difficulty' problems and asked students to 'talk through' their solutions. At higher education level, many universities attempt to diagnose the mathematical difficulties of individual students on entry to their programmes (e.g. Appleby et al, 1997), whilst Leopold and Edgar (2008) and Tariq (2008) have looked systemmatically at the mathematical errors made by cohorts of students of chemistry and biosciences respectively. Lists of common errors have been produced (e.g. Schechter, 2009) and several authors have identied particular threshold topics e.g. algebra (Lins, 1992) or graphs (Gill, 1999a) which they believe correlate well with success in subsequent study.

\section{Context}

The work described in this paper offers particular insight because it is an attempt to identify the errors made by adult students of science, from all over the world and with widely varying ages and mathematical backgrounds. This means that blame for weak mathematics cannot be attributed to a particular educational system, whilst there is every incentive to find out as much as possible about where the misunderstandings lie.

The students were studying a 10-credit (100 hours of study) Maths for Science module at the UK Open University (OU). This module is in line with most of the OU's undergraduate curriculum in that it has no entry qualifications, though students are advised to take it after the introductory science module Exploring science and in preparation for higher level study of science. The age distribution of the 322 students on the presentation of Maths for Science that started in October 2012 is given in Figure 1. Seventy-two of the students $(22 \%)$ had previous educational qualifications below those normally assumed on entry to UK universities and although the majority (239 students i.e. $74 \%$ ) were studying in England, 32 (10\%) were in Scotland and $33(10 \%)$ were outside the UK.

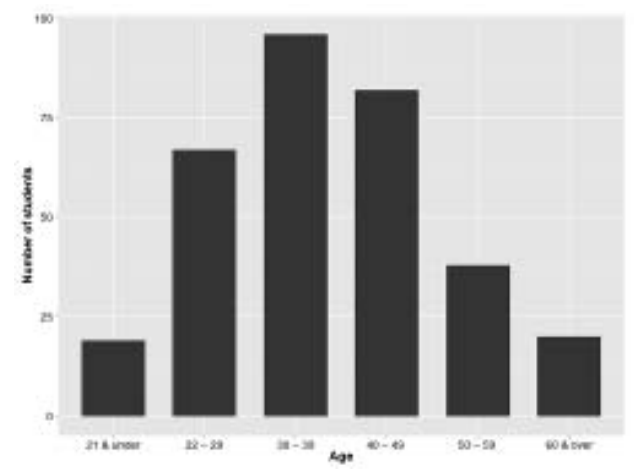

Figure 1. The age distribution of the 322 students on the October 2012 presentation of Maths for Science

The edition of Maths for Science offered to students from October 2012 is a slightly modified version of a successful module which ran in four presentations per year from 2002-2012 and was studied by more than 12,000 students, of similarly varied background to that described above.

The book on which the module is based (revised for the new version of the module as Jordan et al, 2013) has the following chapters:

1. Starting points [Numbers; Fractions; Powers, reciprocals and roots; Doing calculations in the right order].

2. Measurement in science.

3. Calculating in science.

4. Unit conversions.

5. Algebra. 
6. Putting algebra to work.

7. Graphs and gradient.

8. Rate of change and differentiation.

9. Angles and trigonometry.

10. Logarithms.

11. Probability and descriptive statistics.

12. Statistical hypothesis testing.

When it was first offered to students in 2002, Maths for Science was the first OU module to use summative and formative interactive computer-marked assignments (iCMAs), though many other modules now also use this method of assessment. The decision to take this approach was based on a wish to give students instantaneous feedback and an opportunity to act on that feedback while it was still fresh in their minds (Gibbs and Simpson, 2004-5) thus acting as a 'tutor at the student's elbow' (Ross et al, 2006 p.125), particularly important in a distance-learning environment. The e-assessment system used developed into the OpenMark system, many of whose features have now been incorporated into the Moodle quiz engine (Butcher, 2008; Hunt, 2012). Maths for Science has a summative iCMA-based end-of-module assessment (EMA), available to students in the final five weeks of the module, and a formative 'practice assessment' which students can access as many times as they want for the duration of the module. In both of these, students receive three tries at each of the questions, with an increasing amount of feedback provided for incorrect answers, as shown in Figure 2. A range of question types is used, with a preference for constructed-response, where students enter their own answer rather than selecting from options provided. Most questions exist in a number of variants, used to deter plagiarism in the summative EMA and to provide extra opportunities for practice in the practice assessment.

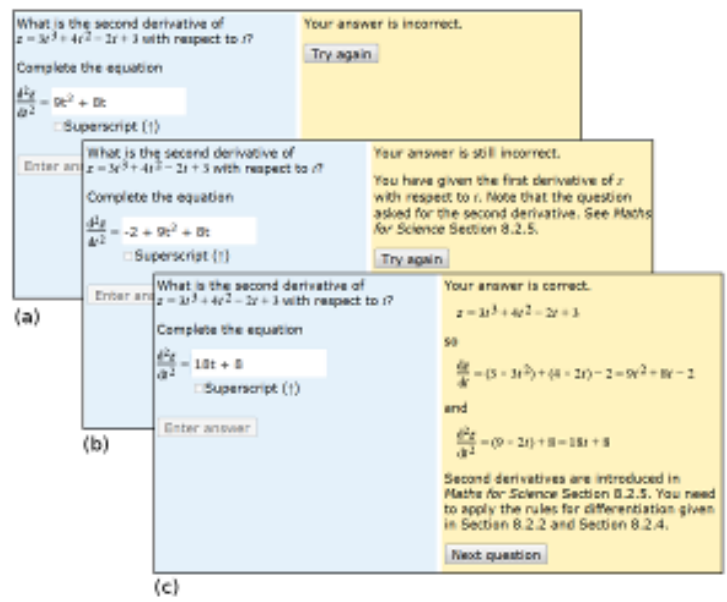

Figure 2. A typical Maths for Science question with increasing feedback after subsequent tries (a)-(c)

The teaching text of Maths for Science was originally developed in the light of known difficulties with mathematics in higher level science modules and from observation and discussion with students as they attempted mathematical problems. Misunderstandings revealed by an early analysis of some of the iCMA questions (Jordan, 2007) led to minor changes when the Maths for Science book was reprinted and also to improvements to the iCMA questions and feedback. For its entire life, Maths for Science has been shown to improve retention in subsequent science modules and it has been well received by students. However the more major rewriting of the book for 2012-13 provided the incentive to review systematically the performance of all the questions in the practice assessment and the two versions of the EMA which had been used on alternate presentations from 2002-2012. The questions were subsequently regrouped, with a small number of new items, into a single EMA for the revised module, an iCMA for another module, and a shared practice assessment. Other changes for the new edition of Maths for Science included a re-ordering of the material and the introduction of a series of screencasts explaining more challenging concepts. 


\section{Method}

Student responses to iCMA questions were analysed for several presentations of Maths for Science, including those that started in February 2010 (262 students) and September 2010 (285 students), which shared one EMA, and May 2010 (478 students) and November 2010 (415 students) which shared a different EMA. Where there were no significant differences between presentations, data from several pre-rewrite presentations were combined in order to increase the data-set and thus to increase the confidence in the results and conclusions. The analyses were repeated for the EMA for the 322 students in the first (October 2012 start) presentation of the revised module. Results were compared with those for similar questions prior to the revision and are discussed when there was a significant change; it was not considered appropriate to combine pre- and post-revision data. However, for clarity in this paper, all results are stated in the order of the teaching in the post-revision module.

For each question in each assignment, two analyses were conducted:

- An analysis of the number of students who got the question right at the first try, second try, third try, or not at all. This was used to give a quick indication of question difficulty and the effectiveness of the feedback provided.

- An inspection of the actual correct and incorrect responses given. This was used to investigate in more detail the errors that students made.

Blank and repeated responses, associated with poor engagement with iCMAs and with weak understanding (Jordan, 2013), were removed prior to the second analysis. Although all questions in the EMAs and the practice assessment were analysed, most of the results reported in this paper are from responses to questions in the summative EMAs, because of a greater confidence that these responses were revealing understanding rather than guesswork. Similarly, constructed-response questions were generally found to be more revealing than selected-response question types such as multiple-choice, because responses constructed by students showed their true understanding rather than their selection of an option created by the question author. Finally, multiple variants of questions were particularly useful when different incorrect responses to the different variants could be attributed to the same mistake or misunderstanding. On some occasions specific errors could be identified more clearly by inspection of the patterns of responses given to each variant.

It is important to distinguish between the error that a student makes and the underlying misconception (Hadjidemetriou and Williams, 2002), especially since some of the errors will inevitably have been as a result of simple slips (Ryan and Williams, 2007) and in other cases, the same incorrect response from different students may have been caused by different misconceptions (MacGregor and Stacey, 1994). Although some attempt will be made to speculate as to the possible underlying misconceptions held by Maths for Science students, the strength of the methodology is the unequivocal identification of common errors, especially given that the same errors were made from presentation to presentation and thus by very large numbers of students, who came from a wide range of different backgrounds and had then studied a common 10-credit module.

\section{Results}

Overview of the assignment

Figure 3 shows the number of students who, for each question in the EMA for the presentation of Maths for Science that started in October 2012, got the question right at the first, second or third try, or not at all. These results are broadly in agreement with similar analyses for other presentations. It is clear that questions on Chapter 1 (arithmetic), Chapter 9 (angles and trigonometry) and Chapter 12 (statistical hypothesis testing) were well answered. In general, students appear to be very good at following the processes required by a particular statistical test, such as a chi-squared test (Questions 37-39) and interpreting the result (Questions 40-41).

Students are often thought to have difficulties in rearranging equations, so it is of considerable interest that the questions on algebra (Chapter 5) were also reasonably well answered. However, questions such as Question 11 in Figure 3, which require students to substitute values into an 
equation without any rearrangement, have persistently been amongst the most poorly answered. Jordan (2007) identified errors in questions of this type as being caused by difficulties in finding the correct units (often linked to difficulties with fractions and reciprocation), giving answers to inappropriate precision, and incorrect use of precedence in arithmetic. Question 11 is discussed further in the following sub-section as are other individual questions showing poor performance, including Question 20 (finding correct units again) and Question 36 (standard deviation).

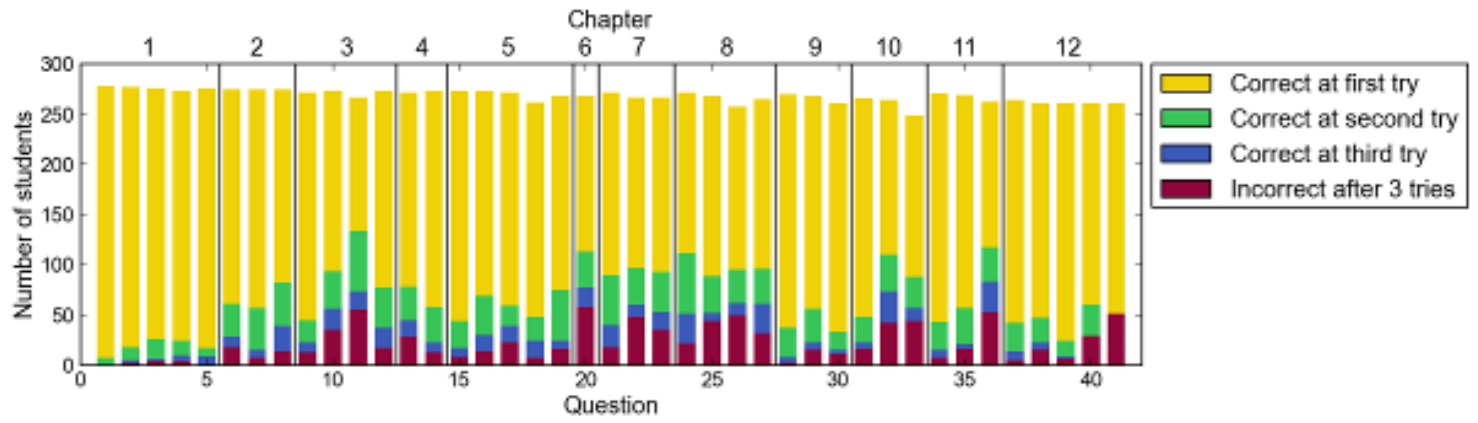

Figure 3. The number of responses that were correct at first, second or third try or not at all, for each question in the EMA (October 2012 presentation)

Chapters whose questions were less well answered overall included Chapter 7 (graphs and gradient) and Chapter 8 (elementary differentiation), whilst two of the three questions on logarithms (Chapter 10) were poorly answered. Both of these questions were selected-response questions, illustrating that selected-response questions are not necessarily easier than constructed-response questions. It was not possible to draw any firm conclusions about the nature of students' misunderstandings from the incorrect responses given to these two questions - it seems likely that many students were out of their depth and so simply guessing.

Analysis of responses to individual questions.

The following subsections consider responses to individual questions, where it has been possible to identify the most common mistakes that were made. The question numbers given relate to the position of a question or a similar one in the EMA for the October 2012 presentation (as shown in Figure 3). Thus 'EMA Q11' describes the question that was Question 11 in this EMA, even though it was actually Question 10 in the earlier EMAs on which the analysis was carried out; 'EMA Q11a' describes a question that was similar to EMA Q11, but used on a different EMA whilst 'PA Q11a' describes a question that was similar to EMA Q11, but used in the practice assessment. Most of the questions exist in several (typically five) variants, but following work to ascertain that the variants were of equivalent difficulty (Jordan et al, 2012), the results are reported as if all for one variant. Thus, for example, EMA Q2 (the first question discussed in the following subsection) is described as requiring students to add $\frac{3}{5}+\frac{2}{3}$, but actually roughly equal number of students received this variant and four similar ones such as $\frac{2}{3}+\frac{5}{7}$.

Chapter 1. Arithmetic fractions. Of 1233 responses to EMA Q2 ('What is $\frac{3}{5}+\frac{2}{3}$ expressed as a single fraction? You should give your answer in the simplest possible form.'), 1098 (89.1\%) were correct. Thus, as shown in Figure 3, this question was well answered. The common errors observed in responses to this question are given in Table 1, with the most frequent mistakes both involving the separate addition of numerators and denominators. 
Table 1. Common errors in 1233 responses to EMA Q2

\begin{tabular}{lcc}
\hline Probable error & Response & $\begin{array}{l}\text { Number of responses } \\
\text { (percentage) }\end{array}$ \\
\hline $\begin{array}{l}\text { Found common denominator then added } \\
\text { numerators and denominators separately }\end{array}$ & $19 / 30$ & $24(1.9 \%)$ \\
$\begin{array}{l}\text { Added numerators and denominators } \\
\text { separately }\end{array}$ & $5 / 8$ & $16(1.3 \%)$ \\
Multiplied the fractions rather than adding & $6 / 15$ & $9(0.7 \%)$ \\
\hline
\end{tabular}

Of 1262 responses to EMA Q3 ('What is $\frac{2}{3} \div 4$ expressed as a single fraction? You should give your answer in the simplest possible form.'), 1106 (87.6\%) were correct. However, as shown in Table 2, it is interesting that the most common error was to fail to give the answer in its simplest form.

Table 2. Common errors in 1262 responses to EMA Q3

\begin{tabular}{lcc}
\hline Probable error & Response & $\begin{array}{l}\text { Number of responses } \\
\text { (percentage) }\end{array}$ \\
\hline $\begin{array}{l}\text { Divided correctly but did not give answer in } \\
\text { the simplest form }\end{array}$ & $2 / 12$ & $51(4.0 \%)$ \\
Multiplied the fractions rather than dividing & $8 / 3$ & $24(1.9 \%)$ \\
\hline
\end{tabular}

Chapter 1. Powers. Of 1259 responses to EMA Q4 ('Evaluate $\left(3^{10}\right)^{1 / 5}$. You should give your answer as a single number.'), 1085 (86.2\%) were correct. The most common errors are given in Table 3, illustrating that whilst the majority of students answered this question well, a significant minority confused multiplication and raising a number to a power. Where students found $3^{10} \times \frac{1}{5}$ instead of $\left(3^{10}\right)^{1 / 5}$, their precedence error was perhaps caused by poor calculator use. As shown in Table 4, similar errors were seen in 16476 responses to a question on the practice assessment, PA Q4a, 'Evaluate 10002/3. You should give your answer as a single number.'

Table 3. Common errors in 1259 responses to EMA Q4

\begin{tabular}{lcc}
\hline Probable error & Response & $\begin{array}{l}\text { Number of responses } \\
\text { (percentage) }\end{array}$ \\
\hline $3 \times 10 \times \frac{1}{5}$ & 6 & $36(2.9 \%)$ \\
$3^{10} \times \frac{1}{5}$ & 11809.8 & $30(2.4 \%)$ \\
$3 \times 10^{10 \times \frac{1}{5}}=3 \times 10^{2}$ & 300 & $14(1.1 \%)$ \\
\hline
\end{tabular}

Table 4. Common errors in 16476 responses to PA Q4a

\begin{tabular}{lcc}
\hline Probable error & Response & $\begin{array}{l}\text { Number of responses } \\
\text { (percentage) }\end{array}$ \\
\hline $1000 \times \frac{2}{3}$ & 666.7 & $770(4.7 \%)$ \\
$1000^{1 / 3}$ & 10 & $615(3.7 \%)$ \\
$\left(1000^{2}\right) \div 3$ & 333333.3 & $226(1.4 \%)$ \\
\hline
\end{tabular}

For EMA Q4a, shown in Figure 4, 1090 (70.6\%) of 1543 responses were entirely correct. However it is noteworthy that whilst 1400 responses $(90.7 \%)$ included one of the correct options, $3^{5} \times 3^{2}$, only 1174 responses $(76.1 \%)$ included the other correct option, $3^{3} \div 3^{-4}$, illustrating that negative powers notation and reciprocation cause difficulty for some students. The most commonly selected incorrect option was $3^{4}+3^{3}$, included in 217 responses $(14.1 \%)$. 


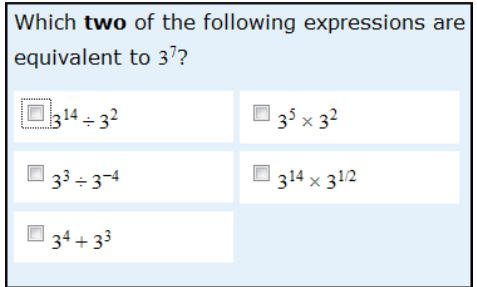

Figure 4. EMA Q4a

Chapter 2. Decimal places, significant figures and rounding. Of 1363 responses to EMA Q6a ('Express 348.7 in scientific notation to three significant figures.'), 871 (63.9\%) were entirely correct. Most students handled scientific notation well, with 1181 responses $(86.6 \%)$ being expressed in correct scientific notation, but significant figures and rounding caused more difficulty. The most common errors are given in Table 5.

Table 5. Common errors in 1363 responses to EMA Q6a

\begin{tabular}{lcc}
\hline $\begin{array}{l}\text { Error(s) (other aspects of the answer } \\
\text { correct) }\end{array}$ & Response & $\begin{array}{l}\text { Number of responses } \\
\text { (percentage) }\end{array}$ \\
\hline Answer given to 4 sig figs (should be 3) & $3.487 \times 10^{2}$ & $98(7.2 \%)$ \\
Answer truncated rather than rounded up & $3.48 \times 10^{2}$ & $98(7.2 \%)$ \\
Answer not in scientific notation & 349 & $64(4.7 \%)$ \\
$\begin{array}{l}\text { Answer not in scientific notation and } \\
\text { truncated rather than rounded up }\end{array}$ & 348 & $17(1.2 \%)$ \\
\hline
\end{tabular}

It has been thought that students might find it more difficult to write a number in scientific notation where the power of 10 was negative, but EMA Q6 ('Express 0.8486 in scientific notation to three significant figures') was in general better answered than EMA Q6a, with 946 (68.9\%) of 1374 responses to EMA Q6 being completely correct. Although some responses gave the incorrect sign for the power of 10 (Table 6) it was apparently less tempting to fail to convert to scientific notation than was the case for EMA Q6a (Table 5). No responses of 0.848 (truncated and not in scientific notation) were observed. EMA Q6 also appeared to be slightly better answered in the presentation that started in October 2012, with 257 (71.4\%) of 360 responses being entirely correct, and proportionally less of each of the errors, perhaps because of more careful teaching on rounding and the introduction of screencasts.

Table 6. Common errors in 1374 responses to EMA Q6

\begin{tabular}{lcc}
\hline $\begin{array}{l}\text { Error(s) (other aspects of the answer } \\
\text { correct) }\end{array}$ & Response & $\begin{array}{l}\text { Number of responses } \\
\text { (percentage) }\end{array}$ \\
\hline Answer given to 4 sig figs (should be 3) & $8.486 \times 10^{-1}$ & $84(6.1 \%)$ \\
Answer truncated rather than rounded up & $8.48 \times 10^{-1}$ & $67(4.9 \%)$ \\
Incorrect sign on power of 10 & $8.49 \times 10^{1}$ & $34(2.5 \%)$ \\
Answer not in scientific notation & 0.849 & $26(1.9 \%)$ \\
\hline
\end{tabular}

Decimal places, significant figures and rounding were found to cause problems throughout the EMA, so two simpler questions were introduced for the presentation that started in October 2012. The first of these, EMA Q8, is shown in Figure 5. Although some caution is necessary in interpreting the results, because of the relatively small number of responses to this question that were available for analysis, these responses bring further insight into where the difficulties lie. 261 (66.1\%) of the 395 responses to this question were completely correct and whilst $375(94.9 \%)$ correctly identified 0.036 as being given to three decimal places and $342(86.6 \%)$ correctly identified 0.036 as being stated to two significant figures, only $309(78.2 \%)$ correctly identified the fact that 4.310 is stated to four significant figures. The most common errors are given in Table 7. 


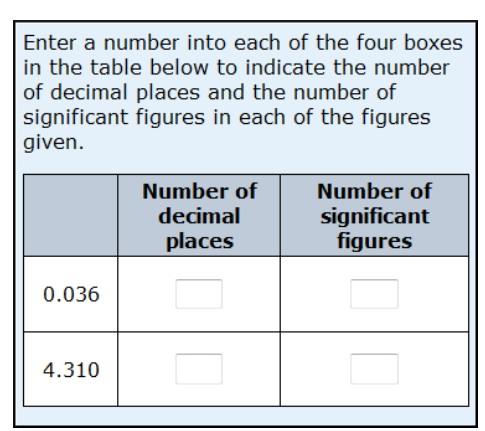

Figure 5. EMA Q8

Table 7. Common errors in 395 responses to EMA Q8

\begin{tabular}{lc}
\hline Error(s) (other aspects of the answer correct) & $\begin{array}{l}\text { Number of responses } \\
\text { (percentage) }\end{array}$ \\
\hline 4.310 identified as being to 3 sig figs & $33(8.4 \%)$ \\
4.310 identified as being to 3 sig figs and 2 & $14(3.5 \%)$ \\
decimal places & $13(3.3 \%)$ \\
4.310 identified as being to 2 decimal places & \\
\hline
\end{tabular}

Chapter 3. Calculating in science. EMA Q10, designed to assess students' ability to manipulate powers of 10, with or without a calculator, and their understanding of order of magnitude, is shown in Figure 6. Of 1678 responses to this question, 968 (57.7\%) gave the correct answer of 13. Table 8 reveals that most students used a calculator, not always correctly, and that the most common error was to give the power of 10 of the calculated value rather than rounding up to the correct order of magnitude.

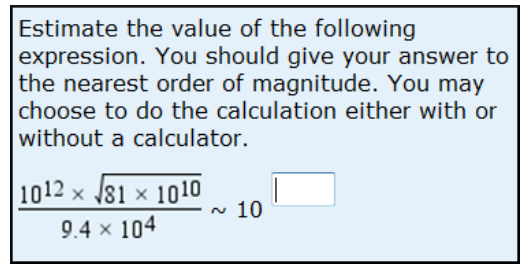

Figure 6. EMA Q10

Table 8. Some of the common errors in 1678 responses to EMA Q10

\begin{tabular}{lcc}
\hline Probable error & Response & $\begin{array}{l}\text { Number of responses } \\
\text { (percentage) }\end{array}$ \\
\hline $\begin{array}{l}\text { Calculated answer as } 9.57 \times 10^{12} \text {, then gave } \\
\text { power of } 10 \text { rather than order of magnitude. }\end{array}$ & 12 & $189(11.3 \%)$ \\
$\begin{array}{l}\text { Entered } 10^{12} \text { into calculator as 10E12 } \\
\left.\text { (i.e. as } 10 \times 10^{12}\right) .\end{array}$ & 14 & $75(4.5 \%)$ \\
$\begin{array}{l}\text { Found } 10^{12} \times \sqrt{81} \times 10^{10} \div\left(9.4 \times 10^{4}\right) \\
\text { Found } 10 \mathrm{E} 12 \times \sqrt{81} \times 10 \mathrm{E} 10 \div\left(9.4 \times 10^{4}\right)\end{array}$ & 18 & $52(3.1 \%)$ \\
$\begin{array}{l}\text { Found } 10 \mathrm{E} 12 \times \sqrt{81} \times 10 \mathrm{E} 10 \div\left(9.4 \times 10^{4}\right) \\
\text { then gave power of } 10 \text { rather than OOM. }\end{array}$ & 19 & $30(1.8 \%)$ \\
\hline
\end{tabular}

EMA Q11, EMA Q11a and PA Q11a, designed to test similar skills, are compared in Figure 7. 


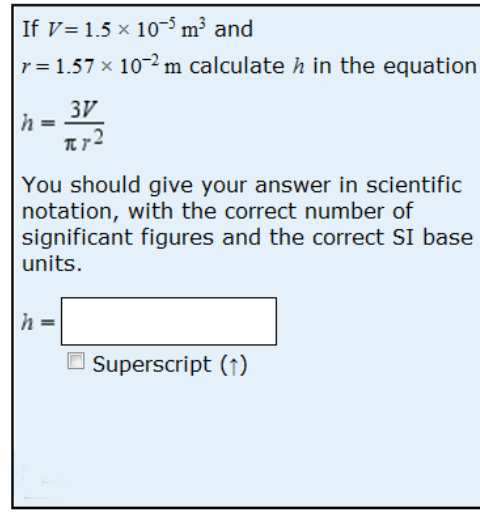

(a)

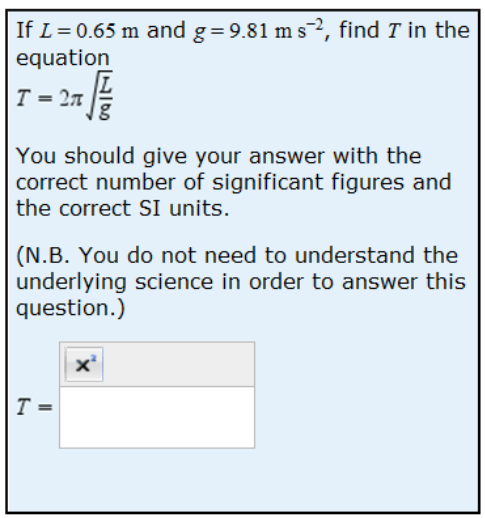

(b)

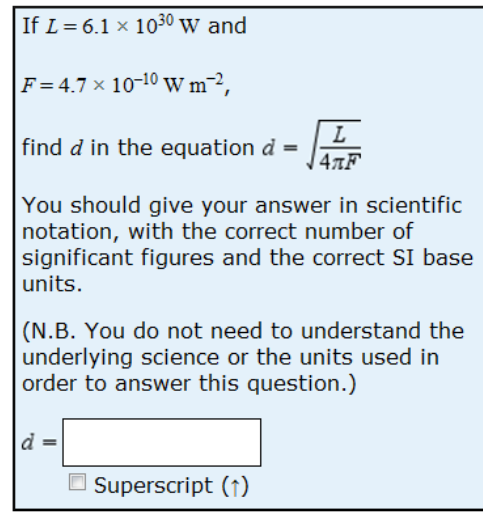

(c)

Figure 7. (a) EMA Q11; (b) EMA Q11a; (c) PA Q11a

None of these questions were well answered, with just 1220 (38.2\%) of 3190 responses giving the correct answer to EMA Q11; 1039 (32.0\%) of 3242 responses giving the correct answer to EMA Q11a; and $3111(38.6 \%)$ of 8054 responses giving the correct answer to PA Q11a. As previously reported (Jordan, 2007), the errors were mostly as a result of problems with units and rounding to an appropriate number of significant figures. However, the different behaviour of the three questions provides additional insight. Common errors to EMA Q11, EMA Q11a and PA Q11 are given in Tables 9, 10 and 11 respectively.

Table 9. Common errors in 3190 responses to EMA Q11

\begin{tabular}{lcc}
\hline $\begin{array}{l}\text { Error(s) (other aspects of the answer } \\
\text { correct) }\end{array}$ & Response & $\begin{array}{l}\text { Number of responses } \\
\text { (percentage) }\end{array}$ \\
\hline Units given as $\mathrm{m}^{2}$ (should be m) & $5.8 \times 10^{-2} \mathrm{~m}^{2}$ & $205(6.4 \%)$ \\
Answer given to 3 sig figs (should be 2) & $5.81 \times 10^{-2} \mathrm{~m}$ & $111(3.5 \%)$ \\
No units & $5.8 \times 10^{-2}$ & $80(2.5 \%)$ \\
Calculated $3 \times V \div \Pi \times r^{2}$ & $3.5 \times 10^{-9} \mathrm{~m}$ & $77(2.4 \%)$ \\
Units given as $\mathrm{m}^{3}$ & $5.8 \times 10^{-2} \mathrm{~m}^{3}$ & $49(1.5 \%)$ \\
\hline
\end{tabular}

Table 10. Common errors in 3242 responses to EMA Q11a

\begin{tabular}{|c|c|c|}
\hline $\begin{array}{l}\text { Error(s) (other aspects of the answer } \\
\text { correct) }\end{array}$ & Response & $\begin{array}{l}\text { Number of responses } \\
\text { (percentage) }\end{array}$ \\
\hline Answer given to 3 sig figs (should be 2 ) & $1.62 \mathrm{~s}$ & $336(10.4 \%)$ \\
\hline Units given as $\mathrm{s}^{-1}$ (should be $\mathrm{s}$ ) & $1.6 \mathrm{~s}^{-1}$ & $169(5.2 \%)$ \\
\hline Units given as $\mathrm{s}^{-2}$ & 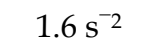 & $156(4.8 \%)$ \\
\hline Units given as $\mathrm{m} \mathrm{s}^{-1}$ & $1.6 \mathrm{~m} \mathrm{~s}^{-1}$ & $109(3.4 \%)$ \\
\hline Answer given to 3 sig figs and units as $\mathrm{s}^{-2}$ & $1.62 \mathrm{~s}^{-2}$ & $97(3.0 \%)$ \\
\hline Answer given to 3 sig figs and units as s $\mathrm{s}^{-1}$ & $1.62 \mathrm{~s}^{-1}$ & $94(2.9 \%)$ \\
\hline Units given as $\mathrm{m} \mathrm{s}^{-2}$ & $1.6 \mathrm{~m} \mathrm{~s}^{-2}$ & $85(2.6 \%)$ \\
\hline Answer given to 3 sig figs and no units & 1.62 & $80(2.5 \%)$ \\
\hline No units & 1.6 & $28(0.9 \%)$ \\
\hline
\end{tabular}

Table 11. Common errors in 8054 responses to PA Q11a

\begin{tabular}{lcc}
\hline $\begin{array}{l}\text { Error(s) (other aspects of the answer } \\
\text { correct) }\end{array}$ & Response & $\begin{array}{l}\text { Number of responses } \\
\text { (percentage) }\end{array}$ \\
\hline No units & $3.2 \times 10^{11}$ & $1296(16.1 \%)$ \\
Units given as $\mathrm{m}^{-2}$ (should be $\left.\mathrm{m}\right)$ & $3.2 \times 10^{11} \mathrm{~m}^{-2}$ & $698(8.7 \%)$ \\
Units given as $\mathrm{m}^{2}$ & $3.2 \times 10^{11} \mathrm{~m}^{2}$ & $571(7.1 \%)$ \\
Incorrect rounding? & $3.3 \times 10^{11} \mathrm{~m}$ & $435(5.4 \%)$ \\
Student has calculated $d^{2}$ rather than $d$ & $1.0 \times 10^{39} \mathrm{~m}^{2}$ & $324(4.0 \%)$
\end{tabular}


(usually with units of $\mathrm{m}^{2}$ )

\begin{tabular}{lcc} 
Answer given to 3 sig figs (should be 2) & $3.21 \times 10^{11} \mathrm{~m}$ & $234(2.9 \%)$ \\
Units given as $\mathrm{m}^{-1}$ & $3.2 \times 10^{11} \mathrm{~m}^{-1}$ & $205(2.5 \%)$ \\
Units given as $\mathrm{W} \mathrm{m}^{-2}$ & $3.2 \times 10^{11} \mathrm{~W} \mathrm{~m}^{-2}$ & $178(2.2 \%)$ \\
\hline
\end{tabular}

EMA Q11a was less well answered than the other two, even though this question was used in a summative EMA. Many responses included multiple errors, but at least 607 responses $(18.7 \%)$ gave an answer to three significant figures rather than the expected two. Significant figure errors were seen in substantially fewer responses to EMA Q11 and hardly at all in responses to PA Q11. This can be explained by the fact that all the input data for PA Q11 was clearly given to two significant figures and, whilst $r$ in EMA Q11 was given to three significant figures, $V$ was clearly given to two significant figures (which, according to the teaching in Maths for Science, means that the answer should be given to two significant figures too). In contrast, in EMA Q11a, $g$ was given to three significant figures, and it appears that many students incorrectly thought that $L=0.65 \mathrm{~m}$ was to three significant figures too, which would mean that the answer should be given to three significant figures.

Many responses to all three questions were incorrect because they gave incorrect units. For EMA Q11a and PA Q11a it is possible to further attribute these errors to problems with finding a reciprocal of a negative power (leading to units of $\mathrm{s}^{-1}$ instead of $\mathrm{s}$ ), taking a square root (leading to units of $\mathrm{m}^{2}$ instead of $\mathrm{m}$ ) or both (leading to units of $\mathrm{s}^{-2}$ instead of $\mathrm{s}$ and $\mathrm{m}^{-2}$ instead of $\mathrm{m}$ ). The fact that students found it more difficult to give their answer to EMA Q11a to an appropriate number of significant figures than was the case for the other two questions was partly compensated for by the fact that $16.1 \%$ of the responses to PA Q11a, $2.5 \%$ of the responses to EMA Q11, but only $0.9 \%$ of the responses to EMA Q11a had omitted units. For PA Q11a, the omission may be attributed to students paying insufficient attention to a purely formative question, whilst for EMA Q11, some students probably thought that the correct answer was dimensionless as opposed to simply forgetting to give units.

There was some evidence of errors with precedence in EMA Q11 (students calculating $3 \times V \div \Pi \times r^{2}$ instead of $3 \times V \div \Pi \div r^{2}$ ). However these appear to have been calculator errors rather than being caused by a fundamental misunderstanding of the nature of the calculation, otherwise the units would have been given as $\mathrm{m}^{5}$, which was not seen.

When EMA Q11 was used in the presentation of Maths for Science that started in October 2012, it was significantly better answered than previously, with 212 (45.7\%) of 464 responses being correct and proportionally less of each of the errors.

Chapter 4. Unit conversions. The question used as EMA Q13 in the presentation that started in October 2012 ('A jug has a volume of $1.01 \times 10^{3} \mathrm{~cm}^{3}$. Express this value in $\mathrm{dm}^{3}$.') had previously been used in the practice assessment, and not surprisingly it was better answered in the EMA (with 244 i.e. 63.2\% of 386 responses being correct) than it had been as PA Q13 (when 5919 of 11551 i.e. 51.2\% of responses were correct). On each occasion, by far the most common incorrect responses were those that were 100 times too large, corresponding to division by 10 rather than by $10^{3}$ i.e. to a conversion from $\mathrm{cm}$ to $\mathrm{dm}$ rather than from $\mathrm{cm}^{3}$ to $\mathrm{dm}^{3}$. When used as EMA Q13, 41 responses $(10.6 \%)$ included this error. The common errors made when the question was used as PA Q13 are given in Table 12.

Table 12. Common errors in 11551 responses to PA Q13

\begin{tabular}{lcc}
\hline Error(s) (other aspects of the answer correct) & Response & $\begin{array}{l}\text { Number of responses } \\
\text { (percentage) }\end{array}$ \\
\hline $\begin{array}{l}\text { Divided by } 10 \text { rather than } 10^{3} \\
\text { Divided by } 10^{2} \text { rather than } 10^{3}\end{array}$ & $1.01 \times 10^{2}$ & $1219(10.6 \%)$ \\
Multiplied by $10^{3}$ (conversion 'the wrong & $1.01 \times 10^{1}$ & $897(7.8 \%)$ \\
way round') & $652(5.6 \%)$ \\
$\begin{array}{l}\text { Multiplied by } 10 \text { (conversion 'the wrong way } \\
\text { round' and linear rather than cubed) }\end{array}$ & $1.01 \times 10^{4}$ & $408(3.5 \%)$ \\
\hline
\end{tabular}


EMA Q13a ("The area of a cricket pitch is $2.6 \times 10^{-2} \mathrm{~km}^{2}$. Express this value in scientific notation in $\left.\mathrm{m}^{2}{ }^{\prime}\right)$ ) showed similar errors (Table 13) to those seen in PA Q13.

Table 13. Common errors in 1582 responses to EMA Q13a

\begin{tabular}{lcc}
\hline Error(s) (other aspects of the answer correct) & Response & $\begin{array}{l}\text { Number of responses } \\
\text { (percentage) }\end{array}$ \\
\hline $\begin{array}{l}\text { Multiplied by } 10^{3} \text { rather than } 10^{6} \text { (i.e. forgot } \\
\text { to square the conversion factor) }\end{array}$ & $2.6 \times 10^{1}$ & $222(14.0 \%)$ \\
Multiplied by $10^{4}$ rather than $10^{6}$ & $2.6 \times 10^{2}$ & $62(3.9 \%)$ \\
$\begin{array}{l}\text { Divided by } 10^{3} \text { instead of multiplying by } 10^{6} \\
\text { (conversion 'the wrong way round' and }\end{array}$ & $2.6 \times 10^{-5}$ & $37(2.3 \%)$ \\
linear rather than squared) & & \\
$\begin{array}{l}\text { Multiplied by } 10^{5} \text { rather than } 10^{6} \\
\text { Answer not in scientific notation }\end{array}$ & $2.6 \times 10^{3}$ & $36(2.3 \%)$ \\
$\begin{array}{l}\text { Divided by } 10^{6} \text { instead of multiplying } \\
\text { (conversion 'the wrong way round') }\end{array}$ & 26000 & $25(1.6 \%)$ \\
\hline
\end{tabular}

Of 1582 responses to EMA Q13a, 977 (61.8\%) were correct, but $222(14.0 \%)$ had not squared the conversion factor and $59(3.7 \%)$ had done the calculation 'the wrong way round', sometimes combining this with failing to square the conversion factor. Some of the other errors may have been caused by misreading from a calculator display, especially since some students clearly did not work in scientific notation. Sadly, there was also evidence of students not checking that their answer was reasonable - playing a game of cricket on a pitch of area $2.6 \times 10^{-5} \mathrm{~m}^{2}$ or $2.6 \times 10^{-8} \mathrm{~m}^{2}$ might be difficult!

EMA Q14 ('A pyroclastic flow from an erupting volcano travels at a speed of $65 \mathrm{~km} \mathrm{hour}^{-1}$. Express this value in $\mathrm{m} \mathrm{s}^{-1}$ to an appropriate number of significant figures.') provides an example of a question whose behaviour was so unexpected that the answer matching was altered prior to the October 2012 presentation. Before this time, only 945 (54.8\%) of 1723 responses were marked as correct, but as Table 14 illustrates, most of the errors were with significant figures rather than with the unit conversion itself. Therefore, for the October 2012 presentation, it was decided to mark as correct responses that were numerically correct but given to more than two significant figures, in addition to those that were given to two significant figures and would have been marked as correct all along. Of the 354 responses received for this presentation, 49 (13.8\%) were numerically correct but given to more than two significant figures. When these were included, a total of 260 responses $(73.4 \%)$ of responses were now marked as correct. The other common errors, including forgetting to convert hour ${ }^{-1}$ to $\mathrm{s}^{-1}$ and performing this part of the unit conversion in the wrong direction, occurred with similar frequency to that observed for earlier presentations.

Table 14. Common errors in 1723 responses to EMA Q14

\begin{tabular}{lcc}
\hline Error(s) (other aspects of the answer correct) & Response & $\begin{array}{l}\text { Number of responses } \\
\text { (percentage) }\end{array}$ \\
\hline $\begin{array}{l}\text { Answer given to too many significant figures } \\
\text { Converted } \mathrm{km} \text { to } \mathrm{m} \text { but did not convert }\end{array}$ & $\begin{array}{c}18.1 \\
\text { hour }{ }^{-1} \text { to } \mathrm{s}^{-1}\end{array}$ & $290(16.8 \%)$ \\
$\begin{array}{l}\text { Out by a factor of } 10 \\
\text { Multiplied by } 3600 \text { rather than dividing by }\end{array}$ & $2.3 \times 10^{4}$ & $42(2.4 \%)$ \\
3600 & & $34(2.0 \%)$ \\
\hline
\end{tabular}

Chapter 5. Algebra. Chapter 5 of Maths for Science includes sections on 'Rearranging equations', 'Simplifying equations' and 'Combining equations' and Figure 8 shows three questions, each associated with one of these subsections. EMA Q15 (shown in Figure 8(a)) is a simple 'rearranging equations' question and $1039(80.4 \%)$ of 1293 responses were correct (and, depressingly, as shown in Table 15, the most common error was to give the incorrect case for the symbols). However, although most of the 'rearranging equations' questions in the EMAs and the practice assessment are of 
necessity selected-response question types (because of the difficulty for students to enter complex algebraic expressions) and therefore not very useful in revealing common misunderstandings, these questions were always relatively well answered, with $75 \%$ or more of responses being correct.

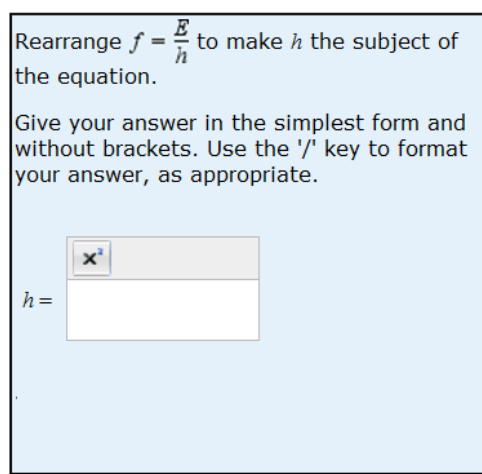

(a)

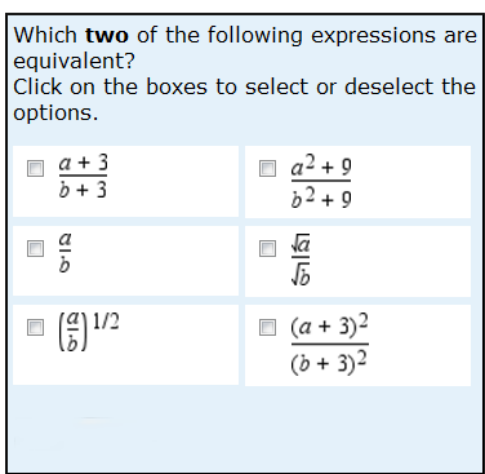

(b)

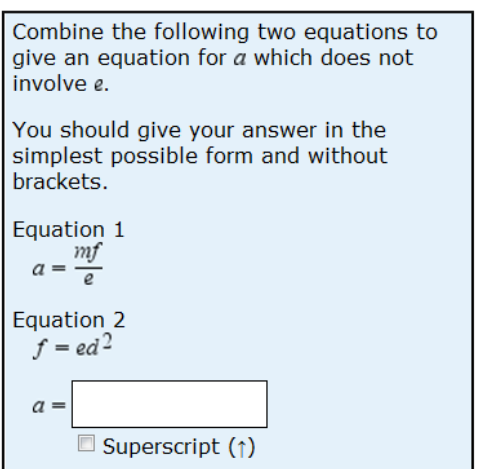

(c)

Figure 8. (a) EMA Q15; (b) EMA Q17a; (c) EMA Q18

Table 15. Common errors in 1293 responses to EMA Q15

\begin{tabular}{lcc}
\hline Probable error & Response & $\begin{array}{c}\text { Number of responses } \\
\text { (percentage) }\end{array}$ \\
\hline $\begin{array}{l}\text { E or } \mathrm{f} \text { given with incorrect case (should } \\
\text { be E/f or E } \mathrm{f}^{-1} \text { ) }\end{array}$ & e/f or E/F & $79(6.1 \%)$ \\
$\begin{array}{l}\text { E multiplied by } \mathrm{f} \text { rather than divided } \\
\text { Reciprocal of correct answer }\end{array}$ & $\mathrm{fE}$ or Ef & $50(3.9 \%)$ \\
\hline
\end{tabular}

For EMA Q17a, shown in Figure 8(b), 955 (59.1\%) of 1615 responses had correctly selected the two equivalent expressions, $\frac{\sqrt{a}}{\sqrt{b}}$ and $\left(\frac{a}{b}\right)^{1 / 2}$. The most commonly selected incorrect expressions, seen together in $275(17.0 \%)$ of responses, were $\frac{(a+3)^{2}}{(b+3)^{2}}$ and $\frac{a^{2}+9}{b^{2}+9}$, revealing a misunderstanding that expressions of the form $(x+y)^{2}$ and $x^{2}+y^{2}$ are equivalent.

For EMA Q18, shown in Figure 8(c), 913 (63.7\%) of 1434 responses were correct i.e. of the form $m d^{2}$ or equivalent, and some common errors are shown in Table 16. Several of the responses indicate that students had difficulty in simplifying their answer. In particular, it appears that a substantial number of students got an equation of the form $a=\frac{m f}{f / d^{2}}$, which is equivalent to the correct answer even though not reached by the simplest method, but which requires further simplification. This simplification caused problems for many, with one apparent cause being that students did not appreciate that the ' $/ d^{2}$ in the fraction's denominator is equivalent to $d^{2}$ in the numerator.

Table 16. Common errors in 1434 responses to EMA Q18

\begin{tabular}{lcc}
\hline Probable error & Response & $\begin{array}{c}\text { Number of responses } \\
\text { (percentage) }\end{array}$ \\
\hline $\begin{array}{l}\text { Incorrect simplification (error in } \\
\text { handling of } / \mathrm{d}^{2} \text { in the denominator) }\end{array}$ & $\mathrm{m} / \mathrm{d}^{2}$ & $131(9.1 \%)$ \\
Incorrect simplification & $\begin{array}{c}\mathrm{mf}^{2} / \mathrm{d}^{2} \text { or } \\
\mathrm{md}^{2} / \mathrm{f}^{2}\end{array}$ & $46(3.2 \%)$ \\
Insufficient simplification & $\begin{array}{c}\mathrm{mf} / \mathrm{f} / \mathrm{d}^{2} \\
\mathrm{mfd}^{2} / \mathrm{f}\end{array}$ & $28(2.0 \%)$ \\
Insufficient simplification & $24(1.7 \%)$
\end{tabular}


Incorrect simplification (f should $\quad \mathrm{mfd}^{2} \quad 23(1.6 \%)$ have cancelled)

Chapter 6. Putting algebra to work. EMA Q20 (Figure 9(a)) requires students to work out the base units for a quantity from a (hypothetical though not unreasonable) equation. This question was added, along with a screencast on 'working out the units', following students' poor performance when asked to work out units in EMA Q11, and similarly poor performance in EMA Q20a (Figure 9(b)), which has been in use for a number of years.

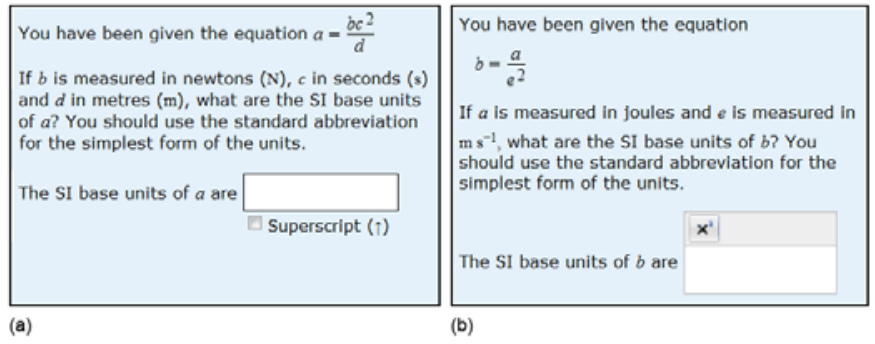

Figure 9. (a) EMA Q20; (b) EMA Q20a

The performance of EMA Q20 for the October 2012 presentation is better than that of EMA Q20a for earlier presentations, with $210(47.4 \%)$ of 443 responses to EMA Q20 in the October 2012 presentation being correct compared with 701 (33.7\%) of 2079 responses to EMA Q20a for earlier presentations. It is not possible to tell whether this improvement is as a result of improved teaching or whether EMA Q20a is a simpler question than EMA Q20. Whatever, there is still scope for improvement here. The most common errors seen in responses to EMA Q20 and EMA Q20a are given in Table 17 and Table 18 respectively.

Table 17. Common errors in 443 responses to EMA Q20

\begin{tabular}{lcc}
\hline Probable error & Response & $\begin{array}{l}\text { Number of responses } \\
\text { (percentage) }\end{array}$ \\
\hline $\begin{array}{l}\text { Correct units but not base } \\
\text { units }\end{array}$ & $\mathrm{N} \mathrm{s}^{2} \mathrm{~m}^{-1}$ & $44(9.9 \%)$ \\
$\begin{array}{l}\text { Base unit equivalent of the } \\
\text { newton (the unit of } b \text { ) }\end{array}$ & $\mathrm{kg} \mathrm{m} \mathrm{s}^{-2}$ & $19(4.3 \%)$ \\
\begin{tabular}{l} 
Capital K (i.e. Kg not $\mathrm{kg}$ ) \\
\hline
\end{tabular} & $\mathrm{Kg}$ & $8(1.8 \%)$ \\
\hline
\end{tabular}

Table 18. Common errors in 2079 responses to EMA Q20a

\begin{tabular}{lcc}
\hline Probable error & Response & $\begin{array}{l}\text { Number of responses } \\
\text { (percentage) }\end{array}$ \\
\hline $\begin{array}{l}\text { Base units for } a / e \text { not } a / e^{2} \\
\text { Base unit equivalent of the }\end{array}$ & $\mathrm{kg} \mathrm{m} \mathrm{s}^{-1}$ & $224(10.8 \%)$ \\
joule (the unit of $a$ ) & $\mathrm{kg} \mathrm{m}^{2}$ s $^{-2}$ & $61(2.9 \%)$ \\
Unknown & $\mathrm{kg} \mathrm{s}^{-1}$ & $50(2.4 \%)$ \\
$\begin{array}{l}\text { Unknown (base unit } \\
\text { equivalent of the newton) }\end{array}$ & $\mathrm{kg} \mathrm{m} \mathrm{s}^{-2}$ & $42(2.0 \%)$ \\
$\begin{array}{l}\text { Unknown } \\
\text { Correct units but not base }\end{array}$ & $\mathrm{J} \mathrm{m} \mathrm{s}^{-1}$ & $41(2.0 \%)$ \\
$\begin{array}{l}\text { units } \mathrm{J} \mathrm{s}^{-2} \\
\text { Capital K (i.e. Kg not kg) }\end{array}$ & $\mathrm{Kg}$ & $39(1.9 \%)$ \\
\hline
\end{tabular}

Chapter 7. Graphs and gradient. EMA Q21 (Figure 10(a)) was correctly answered in 968 (67.7\%) of 1430 responses. A range of numerical values were accepted as correct and units were accepted as $\mathrm{m} / \mathrm{s}$ or $\mathrm{m} \mathrm{s}^{-1}$. The commonly observed errors are given in Table 19, though it should be noted that many responses contained multiple errors, so the percentages given for each error are almost certainly 
underestimates. The most common error was to calculate the gradient as if the line went through the origin, perhaps because students were just calculating distance/time, revealing a lack of understanding of the nature of gradient.

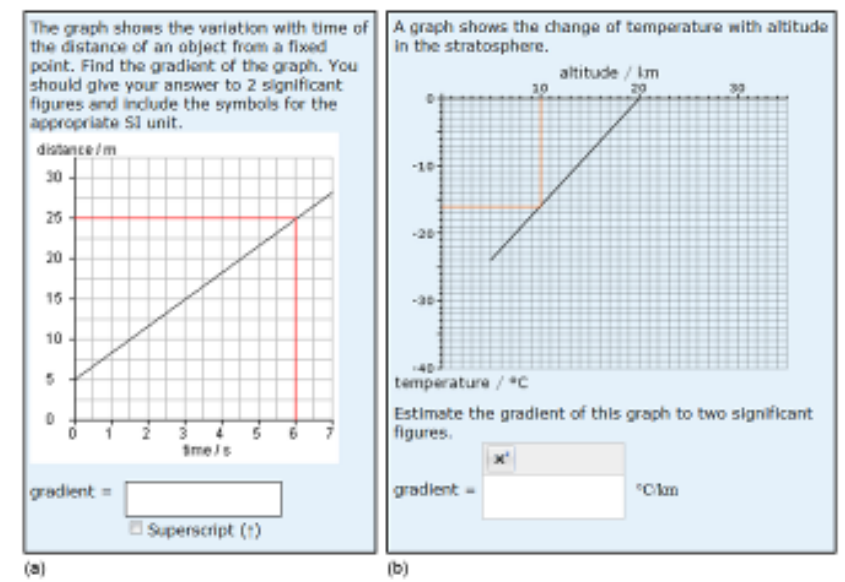

Figure 10. (a) EMA Q21; (b) EMA Q21a

Table 19. Common errors in 1430 responses to EMA Q21

\begin{tabular}{lcc}
\hline Probable error & Response & $\begin{array}{l}\text { Number of responses } \\
\text { (percentage) }\end{array}$ \\
\hline Gradient calculated as if line & $4.2 \mathrm{~m} \mathrm{~s}^{-1}$ & $85(5.9 \%)$ \\
went through the origin & & \\
Incorrect units & $3.3 \mathrm{~m} \mathrm{~s}^{-1}$ & $76(5.3 \%)$ \\
Incorrect significant figures & $3.33 \mathrm{~m} \mathrm{~s}^{-1}$ & $57(4.0 \%)$ \\
No units & 3.3 & $36(2.5 \%)$ \\
\hline
\end{tabular}

EMA Q21a (Figure 10(b)) was correctly answered in 941 (59.9\%) of 1571 responses. The most common errors (Table 20) again illustrate a lack of understanding of the concept of gradient, in this case with many students incorrectly believing the gradient to be negative because the values plotted (in this case for temperature in ${ }^{\circ} \mathrm{C}$ ) are negative.

Table 20. Common errors in 1571 responses to EMA Q21a

\begin{tabular}{lcc}
\hline Probable error & Response & $\begin{array}{l}\text { Number of responses } \\
\text { (percentage) }\end{array}$ \\
\hline $\begin{array}{l}\text { Negative equivalent of } \\
\text { correct answer }\end{array}$ & -1.6 & $264(16.8 \%)$ \\
$\begin{array}{l}\text { Reciprocal of correct answer } \\
\begin{array}{l}\text { Negative reciprocal of } \\
\text { correct answer }\end{array}\end{array}$ & 0.63 & $42(2.7 \%)$ \\
\hline
\end{tabular}

EMA Q23, shown in Figure 11, was designed to test students' understanding of the relationship between straight-line graphs and their equations. Both correct options were selected in $880(57.4 \%)$ of 1532 responses, though unsurprisingly (since the proportionality follows directly from the equation given in the question) more students appreciated that a graph of $F_{\mathrm{m}}$ against $1 / r$ would be a straight line going through the origin than appreciated that $r$ against $1 / F_{\mathrm{m}}$ would be a straight line going through the origin (Table 21). 


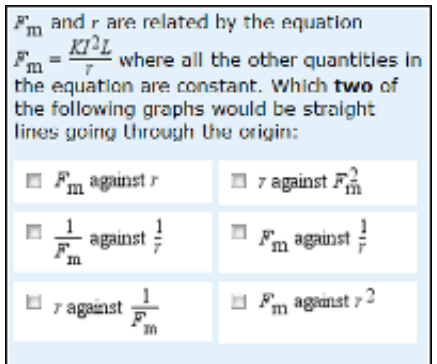

Figure 11. EMA Q23

Table 21. Number of responses, from a total of 1532 for EMA Q23, which included each option

\begin{tabular}{lc}
\hline Option & $\begin{array}{l}\text { Number of responses which } \\
\text { included this option (percentage) }\end{array}$ \\
\hline$F_{\mathrm{m}}$ against $1 / r$ (correct) & $1112(72.6 \%)$ \\
$r$ against $1 / F_{\mathrm{m}}$ (correct) & $1028(67.1 \%)$ \\
$F_{\mathrm{m}}$ against $r$ & $326(21.3 \%)$ \\
$1 / F_{\mathrm{m}}$ against $1 / r$ & $256(16.7 \%)$ \\
$F_{\mathrm{m}}$ against $r^{2}$ & $181(11.8 \%)$ \\
$r$ against $F_{\mathrm{m}}{ }^{2}$ & $136(8.9 \%)$ \\
\hline
\end{tabular}

It is interesting that the most commonly chosen incorrect response to EMA Q23 was that a graph of $F_{\mathrm{m}}$ against $r$ would be a straight line going through the origin. However, this question illustrates the difficulty of trying to gain insight into student misunderstandings from selected-response questions; it seems likely that some students were guessing whilst others were encouraged to select options by their presence in the question. It is difficult to relate the options chosen to students' true understanding.

Chapter 8. Differentiation. EMA Q24 (Figure 12) is, like EMA Q23, a selected response question. However on this occasion, the pattern of option choice gives a clear indication of the nature of students' misunderstandings. The number of times that each option was selected is given in Table 22, but it is the combination of options that gives the clearest insight. Of 1438 responses to this question, $868(60.4 \%)$ correctly identified the three points at which $\frac{\mathrm{d} y}{\mathrm{~d} x}=0$ as B, D and G, but this was followed by $312(21.7 \%)$ responses that all gave the options $\mathrm{A}, \mathrm{C}$ and $\mathrm{E}$, with no other combination being seen in more than $3 \%$ of responses. Points $\mathrm{A}, \mathrm{C}$ and $\mathrm{E}$ are the points at which $\mathrm{y}$ itself is equal to zero, as opposed to $\frac{\mathrm{d} y}{\mathrm{~d} x}$ being zero. A substantial minority of students are thus confusing a point on a graph with the gradient at that point.

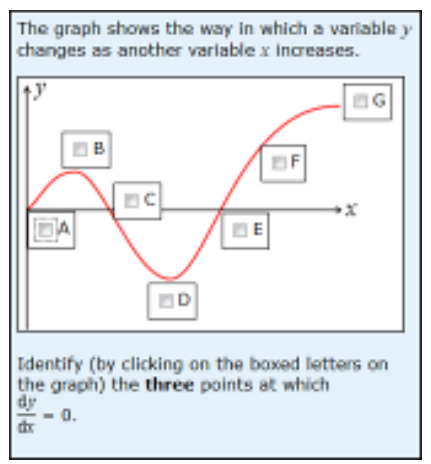

Figure 12. EMA Q24 
Table 22. Number of responses, from a total of 1438 for EMA 24, which included each option

\begin{tabular}{lc}
\hline Option & $\begin{array}{c}\text { Number of responses which } \\
\text { included this option (percentage) }\end{array}$ \\
\hline D (correct) & $1051(73.1 \%)$ \\
B (correct) & $1046(72.7 \%)$ \\
G (correct) & $963(67.0 \%)$ \\
A & $443(30.8 \%)$ \\
E & $395(27.5 \%)$ \\
C & $377(26.2 \%)$ \\
F & $103(7.2 \%)$ \\
\hline
\end{tabular}

Of 1434 responses to EMA Q26 ('If $z=3 t^{2}+5 t+6$, what is the gradient of a graph of $z$ against $t$ at $\left.t=2 .{ }^{\prime}\right), 683(47.6 \%)$ gave the correct response. However, the same fundamental error that was seen in EMA Q24 is seen in the $95(6.6 \%)$ responses that evaluated $z$ rather than $\frac{\mathrm{d} z}{\mathrm{~d} t}$ at $t=2$, as shown in Table 23 .

Table 23. Common errors in 1434 responses to EMA Q26

\begin{tabular}{lcc}
\hline Probable error & Response & $\begin{array}{c}\text { Number of responses } \\
\text { (percentage) }\end{array}$ \\
\hline Evaluated $z$ rather than $\frac{\mathrm{d} z}{\mathrm{~d} t}$ & 28 & $95(6.6 \%)$ \\
Coefficient of first term of $\frac{\mathrm{d} z}{\mathrm{~d} t}$ (error more & 6 & $76(5.3 \%)$ \\
clearly identified in other variants) & & \\
\hline
\end{tabular}

Chapter 9. Angles and trigonometry. Of 1414 responses to EMA Q28a ('Convert an angle of $3.8^{\circ}$ to radians. Give your answer to two significant figures.'), 997 (70.5\%) gave the correct answer of 0.066 . The most common errors are given in Table 24, illustrating the persistence of errors with significant figures and rounding.

Table 24. Common errors in 1414 responses to EMA Q28a

\begin{tabular}{lcc}
\hline Error(s) (other aspects of the answer correct) & Response & $\begin{array}{c}\text { Number of responses } \\
\text { (percentage) }\end{array}$ \\
\hline Answer to 2 decimal places not 2 sig figs & 0.07 & $149(10.5 \%)$ \\
Either incorrect rounding or approximate value & 0.067 & $34(2.4 \%)$ \\
$\begin{array}{l}\text { used for п (answer close but not correct) } \\
\text { Answer to more than 2 sig figs }\end{array}$ & 0.0663 & $11(0.8 \%)$ \\
\hline
\end{tabular}

Of 1491 responses to EMA Q29a (Figure 13), 939 (63.0\%) gave the correct answer of 39 metres. The most common errors are given in Table 25. Students who calculated $d \times \tan \theta$ instead of $d / \tan \theta$ may have incorrectly rearranged the equation $\tan \theta=d / h$ or they may have calculated the tangent of the incorrect angle. If the former, it is interesting that the principle errors are not with trigonometry but with algebra and rounding. 


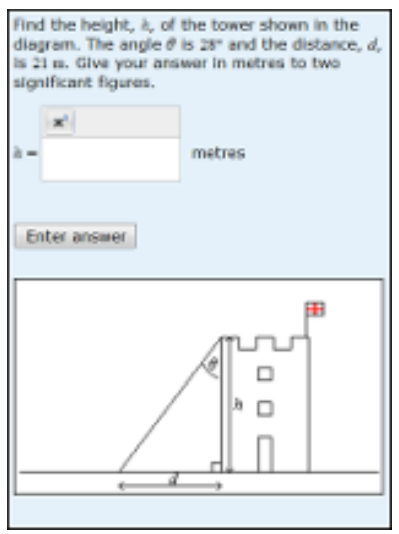

Figure 13. EMA Q29a

Table 25. Common errors in 1491 responses to EMA Q29a

\begin{tabular}{lcc}
\hline $\begin{array}{l}\text { Error(s) (other aspects of the } \\
\text { answer correct) }\end{array}$ & Response & $\begin{array}{l}\text { Number of responses } \\
\text { (percentage) }\end{array}$ \\
\hline $\begin{array}{l}\text { Calculated } d \tan \theta \text { instead of } d / \tan \theta \\
\text { Rounding error }\end{array}$ & 11 & $122(8.2 \%)$ \\
Answer to more than 2 sig figs & 30.49 & $93(6.2 \%)$ \\
\hline
\end{tabular}

EMA Q28a and EMA Q29a were not used the October 2012 presentation of Maths for Science, so it is not possible to assess the impact of the improved teaching, seen to reduce errors with significant figures and rounding in some earlier questions.

Chapter 11. Probability and statistics. Of 1315 responses to Q35 (Figure 14), 962 (73.2\%) gave the correct answer of $1 / 78$. The most common errors are given in Table 26, with the most frequent being to use the addition rule for probability rather than the multiplication rule.

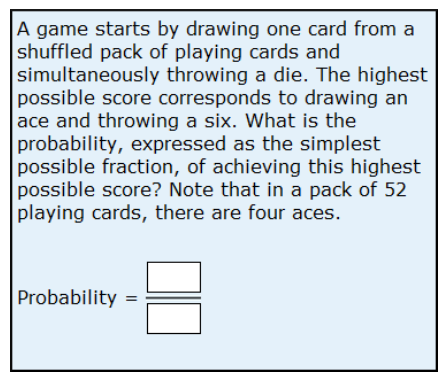

Figure 14. EMA Q35

Table 26. Common errors in 1315 responses to EMA Q35

\begin{tabular}{lcc}
\hline Probable error & Response & $\begin{array}{l}\text { Number of responses } \\
\text { (percentage) }\end{array}$ \\
\hline $\begin{array}{l}\text { Added fractions rather than } \\
\text { multiplying }\end{array}$ & $\frac{19}{78}$ & $81(6.2 \%)$ \\
Used $\frac{1}{52}$ rather than $\frac{1}{13}$ & $\frac{1}{312}$ & $66(5.0 \%)$ \\
Added numerators and denominators & $\frac{5}{58}$ & $15(1.1 \%)$ \\
separately $\left(\frac{4}{52}+\frac{1}{6}\right)$ & & \\
\hline
\end{tabular}


The analysis of responses was based on a slightly differently worded version of EMA Q35 from that shown in Figure 14. The earlier version did not explain that there are four aces in a pack of playing cards but instead referred students to the Maths for Science book for the description of a park of cards. It therefore seems likely that students who used 1/52 rather than 1/13 had misunderstood what the question was asking rather than making a mistake with the mathematics. The revised wording of the question was introduced prior to the October 2012 presentation and this resulted in substantial reduction of errors of this sort, with just one $(0.3 \%)$ of the 342 responses using $1 / 52$ rather than 1/13. However the question's overall success rate was similar, with 253 (74.0\%) of responses being correct, and the other errors occurring in similar proportions. It is interesting that some students attempted to add the fractions rather than multiplying, but then added numerators and denominators separately. This error was seen in much earlier questions (e.g. EMA Q2) but given that a double error is required for this mistake to be seen in EMA Q35, it was in a sense a more common mistake here.

Maths for Science teaches students how to calculate the standard deviation, $\sigma$, of a series of repeated measurements, and this is assessed in EMA Q36 (Figure 15(a)). The module also teaches students how to use measurements from a sample to find the estimated standard deviation, $s$, of a larger population, and this is assessed in PA Q36 (Figure 15(b). Both questions were very poorly answered, with just $814(49.7 \%)$ of 1637 responses to EMA Q36 giving the correct answer of $\sigma=0.0420$ and just $1883(37.4 \%)$ of 5037 responses giving the correct answer of $s=2.83$.

The common errors in EMA Q36 and PA Q36 are given in Table 26 and 27 respectively. Students appeared to confuse the two different standard deviations, to make errors in rounding to the required number of decimal places, or to make both of these errors. In the rewrite prior to the October 2012 presentation, an attempt was made to improve the distinction between the two types of standard deviation, but this did not lead to an improvement in the accuracy of responses to EMA Q36. Of 447 responses, $210(47.0 \%)$ had correctly calculated $\sigma$ whilst $59(13.2 \%)$ had calculated $s$.

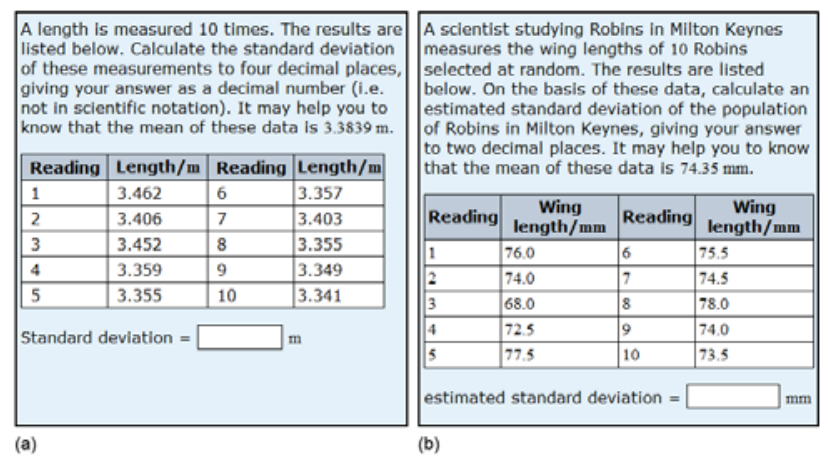

Figure 15. (a) EMA Q36; (b) PA Q36

Table 26. Common errors in 1637 responses to EMA Q36

\begin{tabular}{lcc}
\hline Probable error & Response & $\begin{array}{l}\text { Number of responses } \\
\text { (percentage) }\end{array}$ \\
\hline Calculated $s$ not $\sigma$ & 0.0443 & $165(10.1 \%)$ \\
3 decimal places not 4 & 0.042 & $49(3.0 \%)$ \\
4 sig figs not 4 decimal places & 0.04203 & $37(2.3 \%)$ \\
$\begin{array}{l}\text { Calculated } s \text { not } \sigma \text { and gave answer } \\
\text { to } 4 \text { sig figs not } 4 \text { decimal places }\end{array}$ & 0.04430 & $24(1.5 \%)$ \\
$\begin{array}{l}\text { Calculated } s \text { not } \sigma \text { and gave answer } \\
\text { to } 3 \text { decimal places not } 4\end{array}$ & 0.044 & $19(1.2 \%)$ \\
\hline
\end{tabular}


Table 27. Common errors in 5037 responses to PA Q36

\begin{tabular}{lcc}
\hline Probable error & Response & $\begin{array}{l}\text { Number of responses } \\
\text { (percentage) }\end{array}$ \\
\hline Calculated $\sigma$ not $s$ & 2.68 & $796(15.8 \%)$ \\
2 sig figs not 2 decimal places & 2.8 & $220(4.4 \%)$ \\
Calculated $\sigma$ not $s$ and gave answer & 2.7 & $148(2.9 \%)$ \\
to 2 sig figs not 2 decimal places & & \\
Answer truncated not rounded up & 2.82 & $118(2.3 \%)$ \\
\hline
\end{tabular}

Chapter 12. Statistical hypothesis testing. The final five questions in each of the assessments take a stepby-step approach through a different statistical test, for example, EMA Q37a-Q41a work through a two-tailed $t$-test for unmatched samples. In EMA Q37a (Figure 16(a)), students are required to calculate the common population variance and in EMA Q38a (Figure 16(b)) they use the correct value for this (which is stated at the beginning of EMA Q38a, so this question is not visible until EMA Q37a has been completed, and similarly throughout this section) to calculate the standard error of the differences in the sample means and so to find the test statistic $t$.

In EMA Q39a (not shown), students find the number of degrees of freedom for the $t$-test. EMA Q40a (Figure 16(c)) then requires them to use a table of critical values to find the probability of obtaining a test statistic of this size by chance if the null hypothesis is true. The final question (EMA Q41a) offers a single attempt at a question with just two options: is there a statistically significant effect (at the 0.05 level) or not?

Of 1256 responses to EMA Q37a, $839(66.8 \%)$ gave the correct answer of 3.546. The most common errors are given in Table 28, with the most frequent being to give the square root of the required value i.e. to find $\sqrt{S_{C}^{2}}$.

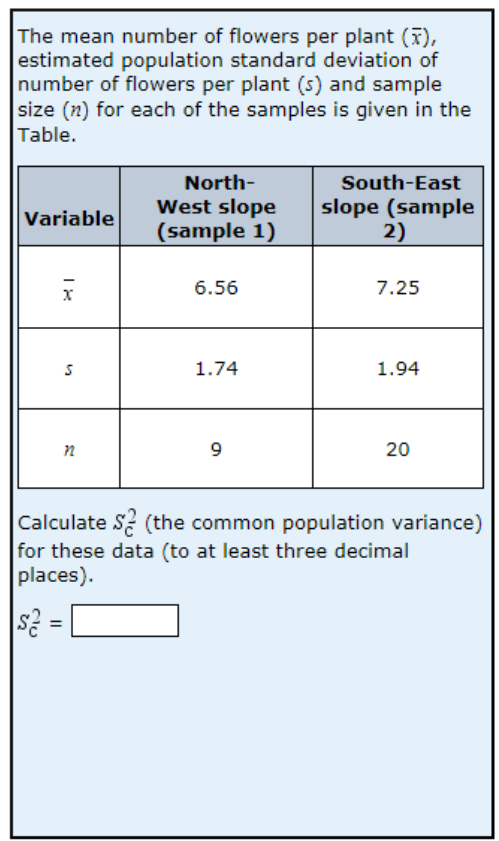

(a)

\begin{tabular}{|c|c|c|}
\hline \multicolumn{3}{|c|}{$\begin{array}{l}\text { Use the correct value of } S_{\mathrm{C}}^{2}=3.546 \text { and any } \\
\text { additional data you require from the Table to } \\
\text { calculate } S E_{\mathrm{D}} \text { (the standard error of the } \\
\text { differences in the sample means) and hence to } \\
\text { find the test statistic } t \text {. }\end{array}$} \\
\hline Variable & $\begin{array}{c}\text { North- } \\
\text { West slope } \\
\text { (sample 1) } \\
\end{array}$ & \begin{tabular}{|c|} 
South-East \\
slope (sample \\
2) \\
\end{tabular} \\
\hline $\bar{x}$ & 6.56 & 7.25 \\
\hline$s$ & 1.74 & 1.94 \\
\hline$n$ & 9 & 20 \\
\hline \multicolumn{3}{|c|}{$\begin{array}{l}\text { You should enter your values for } S E_{\mathrm{D}} \text { and } t \text { to } \\
\text { at least three decimal places. Note that the } \\
\text { marks for this question will be awarded solely } \\
\text { on the basis of whether the value you give for } t \\
\text { is correct. However, if the value you give for } t \\
\text { is incorrect, your answer for } S E_{\mathrm{D}} \text { will be used to } \\
\text { check whether or not you are on the right } \\
\text { lines. }\end{array}$} \\
\hline \multicolumn{3}{|l|}{$S E_{\mathrm{D}}=\square$} \\
\hline$t=\square$ & & \\
\hline
\end{tabular}

(b)

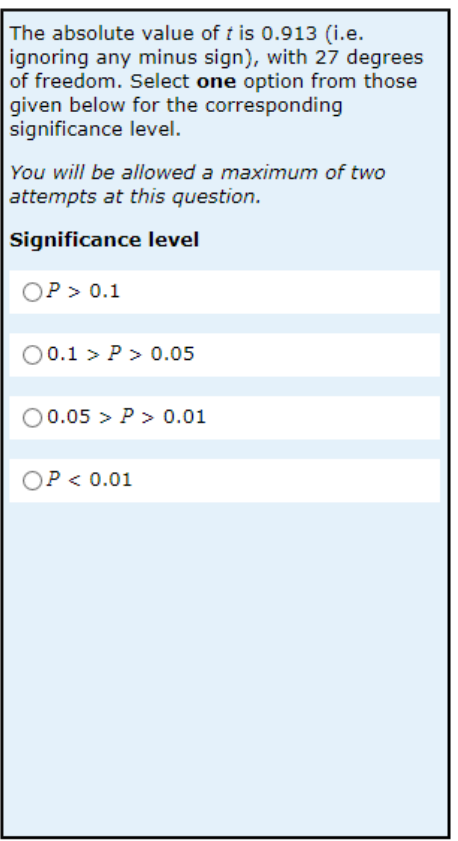

(c)

Figure 16. (a) EMA Q37a; (b) EMA Q38a; (c) EMA Q40a 
Table 28. Common errors in 1256 responses to EMA Q37a

\begin{tabular}{lcc}
\hline Probable error & Response & $\begin{array}{l}\text { Number of responses } \\
\text { (percentage) }\end{array}$ \\
\hline$\sqrt{S_{C}^{2}}$ not $S_{C}^{2}$ & 1.881 & $78(6.2 \%)$ \\
Answer truncated not rounded up & 3.545 & $31(2.5 \%)$ \\
3 sig figs not 3 decimal places & 3.55 & $27(2.1 \%)$ \\
\hline
\end{tabular}

Of 1153 responses to Q38a, 843 (73.1\%) gave a correct answer for $t$, with a further 65 responses $(5.6 \%)$ giving a correct value for $S E_{\mathrm{D}}$, but making an error in the calculation of $t$. The most common errors are given in Table 29. The appearance of a precedence (or calculator) error at this stage of the EMA is interesting, with students finding $\bar{x}_{1}-\frac{\bar{x}_{2}}{S E_{\mathrm{D}}}$ instead of $\frac{\bar{x}_{1}-\bar{x}_{2}}{S E_{\mathrm{D}}}$.

Table 29. Common errors in 1153 responses to EMA Q38a

\begin{tabular}{lc}
\hline Probable error & $\begin{array}{l}\text { Number of responses } \\
\text { (percentage) }\end{array}$ \\
\hline Assumed given value was for $S_{C}$ not $S_{C}^{2}$, so squared again & $21(1.8 \%)$ \\
$\bar{x}_{1}-\frac{\bar{x}_{2}}{S E_{\mathrm{D}}}$ instead of $\frac{\bar{x}_{1}-\bar{x}_{2}}{S E_{\mathrm{D}}}$ & $15(1.3 \%)$ \\
\hline
\end{tabular}

EMA Q39a is a selected-response (multiple-choice) question and the number and proportion of responses which selected each option are shown in Table 30.

The critical values of $t$ for 27 degrees of freedom are given in the table of critical values as 1.703 for $P=0.1,2.052$ for $P=0.05$, and 2.771 for $P=0.01$, thus $78.4 \%$ of responses were right to conclude that the calculated value for $t$ of 0.913 implies that $P>0.1$. However, since the critical values increase as the probability decreases, it is perhaps not surprising that some students interpreted the table as implying that $P<0.1$ and so selected the next most popular option, $0.1>P>0.05$. Since there is a relatively high probability of the result occuring by chance, the null hypothesis cannot be rejected and so the correct answer to EMA Q41 is that there is not a statistically significant difference, in this case between the mean numbers of flowers on the north-west and south-east slopes of a ridge. Of 905 responses, $782(86.4 \%)$ gave the correct answer.

Table 30. Number of responses, from a total of 1081 for EMA 40a, which selected each option

\begin{tabular}{lc}
\hline Option & $\begin{array}{l}\text { Number of responses which had } \\
\text { selected this option (percentage) }\end{array}$ \\
\hline$P>0.1$ (correct) & $848(78.4 \%)$ \\
$0.1>P>0.05$ & $120(11.1 \%)$ \\
$0.05>P>0.01$ & $60(5.6 \%)$ \\
$P<0.01$ & $53(4.9 \%)$ \\
\hline
\end{tabular}

\section{Discussion and conclusions}

Errors seen in the Maths for Science questions include many that have been reported by others so, for example, students' difficulties with logarithms have been reported by Tariq (2003) and Leopold and Edgar (2008), whilst difficulties with basic calculus are as reported by Baker et al (1973) and Hoban et al (2013).

Many of the observed errors are, as expected, in line with those made by schoolchildren, for example separately adding the numerator and denominators of fractions (Hart, 1981a; Swan, 2001) and confusing multiplication with raising a number to a power i.e. not appreciating that $3 x$ and $x^{3}$ are different (Sawyer, 1964; MacGregor and Stacey, 1994). Elsewhere, the difficulty that students have with rounding is reminiscent of Brown's (1981b) observation that children struggle to add one to a 
meter reading of 06399 , whilst the difficulty of converting units of area and volume, also observed by Tariq (2008), is clearly related to the difficulty, reported by Hart (1981b), that children have when asked to decide how many small cubes would fit in a larger one.

Küchermann (1981) and MacGregor and Stacey (1997) have both reported student difficulties with the different meanings that can be assigned to letters and symbols. This offers some explanation of Maths for Science students' problems with units and also of the fact that they are less adept at simplifying than rearranging equations. Others e.g. Bradis et al (1999) and Schechter (2009) have observed students' tendency to over-simplify and cancel inappropriately, resulting in errors of the type $(x+y)^{2}=x^{2}+y^{2}$ and $\frac{a^{2} x}{b^{2}+c x}=\frac{a^{2}}{b^{2}+c}$. Everyday language, for example that a fraction is single numerator divided by a single (larger) denominator (Pimm, 1987) further adds to the confusion. Finally, when a student is required, say, to divide by an algebraic fraction, they need to be able to understand the calculation for an arithmetic fraction and then to make the connection between arithmetic and algebra (Sawyer 1964).

Errors seen in Maths for Science questions on graphs and differentiation demonstrate several of the difficulties reported by Kerslake (1981): 'Graphical prototypes' (e.g. assuming that all graphs go through the origin); 'slope-height confusion' and problems with the equation of a straight line. McDermott et al (1987) also explore students' difficulties in making the connection between graphs and physical concepts, again pointing out the difficulty that students have in discriminating between a value on a curve, especially when that value is a height, and the gradient at that point.

It is possible to attempt to classify the errors observed in Maths for Science questions into separate categories, for example, careless mistakes (Ryan and William's (2007) 'slips'); a lack of understanding of a method taught in the module materials (or a misremembered method from years ago); and deeper conceptual misunderstandings. However there is considerable blurring of the boundaries between the categories and there are many examples of questions where it is difficult to be certain whether the common errors observed were a result of conceptual misconceptions, faulty memory or careless errors (Hadjidemetriou and Williams, 2002).

It seems likely that most of the precedence errors observed in Maths for Science were simply careless calculator slips, since the matching errors in units were not seen. It is unfortunate that students seem reluctant to check that their answers are reasonable, even though checking and estimating are taught in the module, and it would be helpful if students understood enough about a calculation in order to 'press the buttons on their calculator in the correct order' (Brown, 1981a, p47). At face value, errors such as typing $\mathrm{Kg}$ instead of $\mathrm{kg}$ (which might not be spotted in a handwritten tutor-marked assignment), or typing $\mathrm{f}=\mathrm{e} / \mathrm{h}$ instead of $\mathrm{f}=\mathrm{E} / \mathrm{h}$, might also be regarded as 'minor' and/or careless. However, they reveal a fundamental lack of awareness of the importance of the meaning of the symbols used for variables and units.

Where students have incorrectly added two fractions, it could be concluded that their fundamental understanding of the nature of fractions and addition is poor. However, for most adult students, the addition of fractions is simply a process, learnt in the module or remembered (or misremembered!) from childhood. The mistake of adding numerators and denominators separately has been reported by many others. However, following the finding that Maths for Science students sometimes start by correctly expressing the fractions to a common denominator but then add numerators and denominators separately, the teaching text was found to be unclear on this point. Improvement in the teaching led to an improvement in the behaviour of the EMA question (Jordan, 2013).

The observed errors in finding the correct standard deviation are mostly attributable to using the incorrect formula, which is an error in mathematical process, linked to a lack of appreciation of the differences between the two standard deviations. 
Errors that appear to be linked to deeper conceptual misunderstandings include a confusion between repeated addition i.e. multiplication (e.g. $3 x$ ) and repeated multiplication i.e. raising to a power (e.g. $x^{3}$ ) and difficulties with reciprocation (Rees and Barr, 1984). Similarly, a deep-rooted misunderstanding of physical properties such as volume and area leads to errors in conversions from, for example, $\mathrm{cm}^{3}$ to $\mathrm{m}^{3}$, and also to errors in working out units. A confusion between the value of a function at a point on a graph and its gradient leads to the common errors observed both in questions on graphs and questions on differentiation.

The most common errors observed in Maths for Science questions were frequently neither related to the question's primary purpose nor what was expected. Errors in rearranging equations were seen in trigonometry questions, faulty addition of fractions was seen in a probability question, precedence errors were seen in a statistics question etc. It is also the case that errors were often at a lower level i.e. with 'easier' mathematics than expected, so not only did students have difficulty expressing a number to an appropriate number of significant figures, they also had difficulty in simply stating the number of decimal places given. Howarth and Smith (1980) identify the widespread nature of problems at a more fundamental level than students are prepared to admit, whilst Leopold and Edgar (2008) point out that many tutors assume that students have a greater fluency in basic mathematics than is actually the case.

There has been much discussion of the advantages and disadvantages of teaching mathematics to science students in a scientific context (e.g. Tariq et al, 2005; Tariq, 2008), as Maths for Science attempts to do. The problem of transfer from one context to another (Britton et al, 2005) means that teaching mathematics in a scientific context does not necessarily help. Hoban et al (2013, p. 33) report that mathematical difficulties experienced by chemistry students may not be caused by problems in transfer to the context of chemistry, but simply to students 'not possessing the necessary mathematical knowledge in a mathematics context.'

Throughout Maths for Science, two groups of errors persist at a level that remains poorly understood: firstly, difficulties in working out the units of a final answer; secondly, problems in giving answers to an appropriate precision. Whilst some reasons for these errors have been suggested, further work is needed in order to understand the reasons for their prevalence and persistence. The Maths for Science book (Jordan et al, 2013) and accompanying resources are now used as part of a larger module Investigative and mathematical skills in science. Here the students have their own tutors and they are assessed partly by tutor-marked assignments. Questions have been added into tutor-marked assignments in an attempt to further explore the difficulties that students have in working out units.

New screencasts, used by both Maths for Science and Investigative and mathematical skills in science, have been well received and point towards the benefits of using a variety of different approaches in teaching mathematics to science students. Another approach, suggested nearly 80 years ago by Benezet (1935-36), would be to introduce more discussion with students, both to learn more about the reasons for their errors and to improve their understanding. Synchronous and asynchronous online tutorials provide a way of enabling such discussion for distance-learning students anywhere in the world.

Thus, interactive computer-marked assessment questions, introduced to improve the assessment and teaching on a Maths for Science module have also provided additional insight into students' mathematical errors. Where the errors are caused by deeper misconceptions, it is not possible from the work reported here, to be absolutely certain as to the nature of these misconceptions. However, given the huge numbers of responses that have been inspected, the fact that similar errors occur in different questions, and the fact that similar errors have been reported elsewhere, it seems that the errors themselves are ubiquitous and we should not ignore them. In the Open University's distance learning context, online tutorials provide a means by which all students can engage in discussion of mathematics in order to improve their understanding. Furthermore, the use of iCMAs can free human markers from the drudgery of routine feedback and marking (Jordan and Mitchell, 2009), saving time for more important work such as discussion with their students. 
Acknowledgements

The author gratefully acknowledges the assistance of Greg Black, Phil Butcher, and Shelagh Ross in writing computer-marked questions for Maths for Science, and the assistance of Richard Jordan in analysing the responses. The work was partly funded by the Centre for Open Learning of Mathematics, Science, Computing and Technology (COLMSCT) and this support is also gratefully acknowledged.

\section{References}

Appleby, J., Samuels, P. and Treasure-Jones, T. (1997). DIAGNOSYS: A knowledge-based diagnostic test of basic mathematical skills. Computers and Education, 28(2), 113-131.

Baker, J., Crampin, M., and Nuttall, J. (1973). A crash course in calculus. International Journal of Mathematical Education in Science and Technology, 4(3), 335-339.

Benezet, L. (1935-36). "The teaching of arithmetic: the story of an experiment." http://www.blog.republicofmath.com/wpcontent/uploads/2011/04/Louis_Benezet_Teaching_of_Arithmetic.pdf, (accessed December 2013). [Originally published as Journal of the National Educational Association, 24(8), 241-244; 24(9), 301-303; 25(1), 7-8.]

Bradis, V., Minkovskii, V. and Kharcheva, A. (1999). Lapses in mathematical reasoning. New York: Dover. [Translation of 2nd Russian edition, 1959.]

Britton, S., New, P., Sharma, M. and Yardley, D. (2005). A case study of the transfer of mathematics skills by university students. International Journal of Mathematical Education in Science and Technology, 36(1), 1-13.

Brown, M. (1981a). Number operations. In K. Hart (Ed.), Children's understanding of mathematics 11-16 (pp. 23-47). London: John Murray.

Brown, M. (1981b). Place value and decimals. In K. Hart (Ed.), Children's understanding of mathematics 11-16 (pp. 48-65). London: John Murray.

Butcher, P. (2008). Online assessment at the Open University using open source software: Moodle, OpenMark and more. Proceedings of the 12th International Computer Assisted Assessment Conference, Loughborough, UK.

Butterworth, B. (1999). The mathematical brain. London: Macmillan.

Croft, A., Harrison, M., and Robinson, C. (2009). Recruitment and retention of students: An integrated and holistic vision of mathematics support. International Journal of Mathematical Education in Science and Technology, 40(1), 109-125.

Cuthbert, R. and MacGillivray, H. (2002). The gap between assumed skills and reality in mathematics learning. In M. Goos and T. Spencer (Eds), Mathematics: making waves - Proceedings of the 19th Biennial Conference of the Australasian Association of Mathematics Teachers Inc., University of Queensland, 13-17 Jan 2003, 60-67.

Dearing, R. (1996). Review of qualifications for 16-19 year olds. Full report. Hayes, UK: SCAA Publications.

Engineering Council (2000). Measuring the mathematics problem. London: The Engineering Council.

Gibbs, G. and Simpson, C. (2004-5). Conditions under which assessment supports students' learning. Learning and Teaching in Higher Education, 1, 3-31.

Gill, O. and O'Donoghue, J. (2007). Service mathematics in Irish universities: Some findings from a recent study. Adults Learning Mathematics - an International Journal, 2(2), 6-19.

Gill, P. (1999a). Aspects of undergraduate engineering students' understanding of mathematics. International Journal of Mathematical Education in Science and Technology, 30(4), 557-563.

Gill, P (1999b). The physics/maths problem again. Physics Education, 34(2), 83-87.

Hadjidemetriou, C. and Williams, J. (2002). Children's graphical conceptions. Research in Mathematics Education, 4(1), 69-87.

Hart, K. (1981a). Fractions. In K. Hart (Ed.), Children's understanding of mathematics 11-16 (pp. 66-81). London: John Murray.

Hart, K. (1981b). Measurement. In K. Hart (Ed.), Children's understanding of mathematics 11-16 (pp. 9-22). London: John Murray.

Hart, K., Brown, M., Küchemann, D., Kerslake, D., Ruddock, G. and McCartney, M. (1981). Children's understanding of mathematics 11-16. London: John Murray.

Hoban, R., Finlayson, O. and Nolan, B. (2013). Transfer in chemistry: a study of students' abilities in transferring mathematical knowledge to chemistry. International Journal of Mathematical Education in Science and Technology, 44(1), 14-35.

Howarth, M. J. and Smith, B. J. (1980). Attempts to identify and remedy the mathematical deficiencies of engineering undergraduate entrants at Plymouth Polytechnic. International Journal of Mathematical Educational in Science and Technology, 11(3), 377-383.

Hunt, T. (2012). Computer-marked assessment in Moodle: Past, present and future. Proceedings of CAA 2012 International Conference, Southampton, UK.

Jordan, S. (2007). The mathematical misconceptions of adult distance-learning science students. Proceedings of the 2006 CETLMSOR Conference, Loughborough, UK, 87-92.

Jordan, S. (2013). Using e-assessment to learn about learning. Proceedings of CAA 2012 International Conference, Southampton, UK.

Jordan, S., Jordan, H. and Jordan, R. (2012). Same but different, but is it fair? An analysis of the use of variants of interactive computer-marked questions. International Journal of eAssessment, 2(1).

Jordan, S. and Mitchell, T. (2009). E-assessment for learning? The potential of short-answer free-text questions with tailored feedback. British Journal of Educational Technology, 40(2), 371-385.

Jordan, S., Ross, S. and Murphy, P. (2013). Maths for science. Oxford: Oxford University Press in association with the Open University.

Kerslake, D. (1981). Graphs. In K. Hart (Ed.), Children's understanding of mathematics 11-16 (pp. 120-136). London: John Murray. 
Küchermann, D. (1981). Algebra. In K. Hart (Ed.), Children's understanding of mathematics 11-16 (pp. 102-119). London: John Murray.

Leopold, D. and Edgar, B. (2008). Degree of mathematics fluency and success in second-semester introductory chemistry. Journal of Chemical Education, 85(5), 724-731.

Lins, R. (1992). A framework for understanding what algebraic thinking is. Unpublished PhD Thesis. University of Nottingham.

McDermott, L., Rosenquist, M., and VanZee, E. (1987). Student difficulties in connecting graphs and physics: examples from kinematics. American Journal of Physics, 55(6), 503-513.

MacGregor, M. and Stacey, K. (1994). Progress in learning algebra: Temporary and persistent difficulties. In Challenges in mathematics education: Constraints on construction - Proceedings of the 17th Annual Conference of the Mathematics Education Research Group of Australasia, Vol. 2, 403-410.

MacGregor, M. and Stacey, K. (1997). Students understanding of algebraic notation: 11-15. Educational Studies in Mathematics, 33(1), 1-19.

OECD (2013). “Programme for International Student Assessment (PISA). 2012 results." http://www.oecd.org/pisa/keyfindings/pisa-2012-results.htm, (accessed December 2013)

Pimm, D. (1987). Speaking mathematically: communication in mathematics classrooms. London: Routledge.

Rees, R. and Barr, G. (1984). Diagnosis and prescription: Some common maths problems. London: Harper and Co.

Ross, S., Jordan, S. and Butcher, P. (2006). Online instantaneous and targeted feedback for remote learners. In C. Bryan and K. Clegg (Eds), Innovative Assessment in Higher Education (pp123-131). London: Routledge.

Ryan, J. and Williams, J. (2007). Children's mathematics 4-15: Learning from errors and misconceptions. Maidenhead, UK: Open University Press.

Sawyer, W. (1964). Vision in elementary mathematics. Harmondsworth, UK: Penguin Books.

Schechter, E. (2009). "The most common errors in undergraduate mathematics" http:// www.math.vanderbilt.edu/ schectex/commerrs/, (accessed December 2013)

Swan, M. (2001). Dealing with misconceptions in mathematics. In P. Gates (Ed.), Issues in mathematics teaching (pp. 147-165). London: Routledge/Falmer.

Tariq, V. (2003). Diagnosis of mathematical skills among bioscience entrants. In LTSN Maths TEAM, Diagnostic Testing for Mathematics (pp. 14-15). Birmingham, UK: LTSN Maths TEAM Project.

Tariq, V. (2008). Defining the problem: Mathematical errors and misconceptions exhibited by first-year bioscience undergraduates. International Journal of Mathematical Education in Science and Technology, 39(7), 889-904.

Tariq, V., Stevenson, J. and Roper, T. (2005). Maths for Biosciences: Towards developing an innovative e-learning resource for post-GCSE students. MSOR Connections, 5(2), 39-43.

Tobias, S. (1978). Overcoming math anxiety. New York: Norton.

Williams, J. and Ryan, J. (2000). National testing and the improvement of classroom teaching: Can they coexist? British Educational Research Journal, 26(1), 49-73.

Williamson, S., Hirst, C., Bishop, P. and Croft, T. (2003). Supporting mathematics education in UK Engineering Departments. Proceedings of International Conference on Engineering Education, July 21-25 2003, Valencia, Spain. 